\title{
As tropelias e assuadas de escolares e garotos na cidade do Rio de Janeiro entre os séculos $\mathbf{X I X}$ e XX
}

\author{
Irma Rizzini \\ Jucinato de Sequeira Marques \\ Vinicius de Moraes Monção \\ Universidade Federal do Rio de Janeiro
}

\section{Resumo}

artigo tem como objetivo apontar algumas contradições existentes entre as experiências dos sujeitos e as práticas escolares e assistenciais dirigidas às infâncias na cidade do Rio de Janeiro, entre os séculos XIX e XX. Ao priorizar, em sua análise, as tensões entre a cultura escolar e as ações dos sujeitos, os castigos escolares emergem como entrave da modernidade educacional. Recorrendo a um corpus documental variado, verificou-se que, longe de representarem um consenso, as práticas escolares e assistenciais, tanto as públicas quanto as particulares, geravam conflitos, interesses e fissuras 159 entre os diferentes atores e setores dedicados à causa da criança.

Palavras-chave: História da educação. Processo de escolarização. Infâncias na cidade do Rio de Janeiro.

\section{Disorders and jokes of schoolchildren and boys in Rio de Janeiro between XIX and XX centuries}

\begin{abstract}
The article aims to point out some contradictions among the experiences of individuals among the school practices and the social care practices toward childhood in Rio de Janeiro city, between the nineteenth and twentieth centuries. By giving priority to analyzing the tensions between the school culture and the actions of individuals, the school punishments emerge as an obstacle to educational modernity. Using a variety of documentary corpus, it has been found that, far from representing a consensus, the school practices and the social care practices, both public and private, generated conflicts, interests and gaps between different actors and sectors dedicated to the children's cause.
\end{abstract}

Keywords: History of education. Schooling process. Childhood in Rio de Janeiro city. 


\section{Bromas y desórdenes de chicos y estudiantes en la ciudad de Río de Janeiro entre los siglos XIX y XX}

\section{Resumen}

El artículo pretende señalar algunas contradicciones existentes entre las experiencias de los sujetos y las prácticas escolares y asistenciales direccionados a las infancias en la ciudad de Río de Janeiro, entre los siglos XIX y XX. Al priorizar el análisis las tensiones entre la cultura escolar y las acciones de los individuos, los castigos escolares emergen como un obstáculo de la modernidad educativa. He utilizado corpus documental distinto y he verificado que lejos de representar un consenso, las prácticas escolares y las acciones asistenciales, tanto públicos como privados, generan conflictos, intereses y rupturas entre los diferentes actores y sectores dedicados a la causa de los niños.

Palabras-claves: Historia de la educación. Proceso de escolarización. Niños en la ciudad de Río de Janeiro.

\section{Introdução}

Ao final do mês de julho de 1873, o Jornal do Comércio deu destaque ao entrevero ocorrido entre um professor e um aluno numa escola do Município da Corte, situada na Rua do Aqueduto, 23. Na verdade, trata-se de uma denúncia de castigo corporal que teria sido infligido ao menino Oscar Ávila no dia 29 de julho. Como o fato assumiu proporções inauditas e extrapolou o acontecido em sala de aula, o caso acabou abarcando o Ministério do Império que acionou o chefe de polícia e o Inspetor-Geral da Instrução Primária e Secundária do Município para investigar o episódio. De pronto, o Inspetor, assumindo as rédeas da apuração dos fatos, solicitou o exame de corpo de delito em Oscar Ávila?'. Ao mesmo tempo, o delegado de polícia realizou diligência no local instando o professor a depor. No dia 2 de agosto de 1873, o educador e diretor do colégio, Charles Neucome Palmer², apresentou, ao delegado, o seu depoimento por escrito. Assim, segue o seu relato:

Sem embargo, do muito que tenho recomendado aos pais e famílias dos meus alunos, que não mandem ao colégio antes de 9 horas da manhã, vem eles quase sempre meia hora antes das aulas e 
Irma Rizzini | Jucinato de Sequeira Marques | Vinicius de Moraes Monção

conservam-se em um pátio contíguo ao estabelecimento durante esse tempo. Aqui e naquele intervalo, em que nem sempre me é possível inspecioná-los envolveram-se muitos dos meninos em uma luta corporal, cujos efeitos continuaram surdamente abertas as aulas. Tendo me afastado da sala por instantes e por necessidade, ao voltar encontro chorando o menino José Pereira da Costa, filho de João Luiz Pereira da Costa, estabelecido na rua do Rosário n ${ }^{\circ} 22$ $B$, informando de que o menino Eduardo Ávila rompera com o livro d'aquele, pelo que, castigando eu a este com um puxão de orelha, enquanto o fazia, vi que o menino Oscar Ávila fazendo gestos indecentes, proferia palavras desonestas e ameaçava-me com o punho; chamei-o a mim, e recusou-se a vir fui-me a ele e tentando tomá-lo pelo braço para encerrá-lo de castigo no quarto, que V. Sa com seus próprios olhos teve ocasião de ver, foi quando ele, buscando evitar-me caiu com o rosto sobre o encosto de uma cadeira e apanhou a contusão que foi vista (CASTIGOS CORPORAIS, 1873, fl. 13).

Antes de prosseguir com sua versão dos fatos, o episódio, que levou o prof. Palmer a tomar medida tão drástica em relação a Oscar Ávila, teve como epicentro outros personagens. Conforme descreve, a origem de todo o ocorrido iniciou-se fora da escola: na rua. Mais precisamente, no pátio, espaço contíguo da escola. Momento em que a escolarização dos sujeitos dá os seus primeiros passos, ou seja, o início da sobreposição das práticas escolares em relação às práticas sociais e costumeiras. Onde o entrelaçamento entre a rua e a escola acirra fendas e tensões entre as experiências dos sujeitos. A rua, por representar a desordem, os vícios, as sombras, etc. A escola, por conceber a disciplina, o conhecimento, a civilidade, as luzes e a regeneração como símbolos da modernidade educacional.

Já no interior da escola, o professor precisou ausentar-se da sala de aula, "por instantes e necessidade", ao retornar encontrou chorando "[...] o menino José Pereira da Costa, filho de João Luiz Pereira da Costa, estabelecido na rua do Rosário n²2 B, informando de que o menino Eduardo Ávila rompera com o livro d'aquele" (CASTIGOS CORPORAIS, 1873, fl. 13). Aqui fica explícita a intenção de Palmer em demonstrar que conhecia os alunos do colégio ao citar o nome completo do pai e informar o local de moradia. Em relação ao Eduardo - irmão do Oscar -, foi imediatamente castigado com um "puxão de orelha." Enquanto o fazia, o Oscar, condescendente com o seu irmão, realizou os tais "gestos indecentes." Tomado pelo braço e conduzido 
As tropelias e assuadas de escolares e garotos na cidade do Rio de Janeiro entre os séculos XIX e XX

ao "castigo no quarto", chegou a cair machucando o seu rosto numa cadeira [...]. Como se isso não bastasse - aproveitando para retornar a narrativa do episódio -, o professor acrescenta:

Não me parecendo digno de maior reparo aquele acontecimento, aliás frequente entre crianças, e não reclamando cuidados à contusão, fiz com que o mesmo Oscar Ávila desse ainda suas lições não tendo todavia sofrido mais castigos e deixei-o ir para casa (CASTIGOS CORPORAIS, 1873, fl. 13).

Mesmo isolado no quarto, Oscar Ávila, sem merecer maiores cuidados da "contusão" sofrida, não foi poupado de suas obrigações escolares. Incumbe registrar que da atitude inicial de Oscar - "gestos indecentes" e "palavras desonestas" -, o professor, como the aprazia, conseguira o seu intento: obediência e que cumprisse, naquele dia, com os seus deveres escolares.

E assim justifica sua atitude:

Cumpre ponderar nesta ocasião que os meninos Ávila bem como outros dos que frequentam meu Colégio, vivem em constante luta física quando vem ou voltam do Colégio, aparecendo constantemente com pequenos ferimentos e contusões sofridas na rua. Não tenho meio de impedir tais desvios que corre aos pais evitar ou punir. O Sr. João Antônio D'Ávila em pessoa tem sido testemunho da que fazem seus filhos na rua, constando-me mesmo que estes foram expulsos do Colégio Almeida Martins por incorrigíveis.

$[\ldots]$

Porque modo viria eu ofender o rosto do menino Oscar? Com as mãos não mo permitem minha educação e meus princípios, com a palmatória, nem se pode conjecturar, não se teria dado uma contusão simples curável em 8 dias.

[...] desagradavelmente impressionados com a malévola notícia do Jornal do Commercio sobre o fato. Já chamei a juízo o Editor desta e mostrarei que o denunciante só teve em vista a difamação mais torpe (CASTIGOS CORPORAIS, 1873, fl. 14).

$\bigcirc$ "estimado" professor, em suas derradeiras palavras, alude a algumas questões que merecem ser comentadas. A primeira delas refere-se aos irmãos Ávila. Para o mencionado mestre, são meninos "incorrigíveis. " 3 Já expulsos do colégio anterior ${ }^{4}$, viviam constantemente em "lutas físicas." Cabe 
salientar que, além deles, essa era uma prática comum entre os meninos do colégio. Assim, aqueles que frequentavam a escola - seguindo a sua leitura - , eram, na sua grande maioria, "desordeiros."

A segunda afirma que esses "desvios" deveriam ser punidos pelos pais. Com a sua complacência, o Sr. João Antônio Ávila, além de testemunhar o descalabro do comportamento dos seus filhos, era o responsável pelo ocorrido. Por último, considera a denúncia a "difamação mais torpe" proferida pelo jornal. Com o intuito de contra-atacar, o professor desqualifica o denunciante, o veículo denunciador, e roga-lhes o descrédito. "Por que ofenderia o rosto do menino Oscar?" Com a mão, a sua "educação" e seus "princípios" não permitiriam. Utilizando a "palmatória", a contusão levaria mais tempo para a cura.

Findas as explicações do professor Palmer, no dia 5 de agosto de 1873, o Inspetor-Geral da Instrução remete ofício ao Ministro do Império e ao delegado de polícia informando os procedimentos adotados a partir do momento em que fora oficiado do sucedido pelo Ministério, no dia 30 de julho. Desde então, solicitara ao delegado o exame de corpo de delito. No dia seguinte, como the compete, realizou sua própria inspeção na escola interrogando o afrontado que confirmou:

[...] ter sido ofendido com socos e bofetões pelo professor Palmer, no dia 29 de julho, ao meio dia mais ou menos, na casa do Colégio a rua S Thereza n. 23; ter ferido o olho quando, empurrado por Palmer, caiu sobre uma cadeira; ser a causa do castigo ou ofensas o ter conversado na ocasião da aula com o companheiro Santos, sendo causa imediata o ter se recusado a ir para o quarto escuro (quarto de castigo) ${ }^{5}$ (CASTIGOS CORPORAIS, 1873, fl. 15-16).

No primeiro dia de agosto, o Inspetor inquiriu quatro meninos da turma de Oscar Ávila e todos ratificaram:

[... que Palmer quis castigar Oscar, levando para o quarto escuro, por estar este conversando e dizendo palavras ofensivas ao pudor; que, opondo-se a Oscar, Palmer agarrou-o pelo braço e empurrou-o, o que da causa a ferir o Oscar na cadeira.

[Um deles], diante de Palmer disse também que este deu bofetões em Oscar; os outros, interpelados a respeito dos ferimentos na cabeça e na face de Oscar, disseram que não prestaram atenção (CASTIGOS CORPORAIS, 1873, fl. 15-16). 
No relato proferido por Palmer, em nenhum momento descreve os "bofetões" dados em Oscar. Um dos meninos que presenciara o ocorrido, diante do professor, afirmou, categoricamente, essa agressão. Aqui tem-se a melhor expressão para o entendimento do processo de escolarização e as contradições estabelecidas entre os sujeitos escolares (professores e alunos) e suas práticas sociais. Em alguns momentos compartilhados e amenizados, em outros, transformados em campo de batalha e de disputas.

Em suas conclusões e de acordo com o que foi exposto, o InspetorGeral pondera: "[...] entendo que Palmer não procedeu bem a escolha [e] os limites [do] castigo permitido a um professor" (CASTIGOS CORPORAIS, 1873, fl. 15-16).

que originou todo o entrevero - o fato de Eduardo Ávila "romper com o livro" de José Pereira da Costa e ganhar um "puxão de orelhas" - ficou sumariamente secundarizado pelo desenrolar dos acontecimentos. Pelo que se depreende, esse caso indica o uso costumeiro, por parte dos sujeitos escolares, de "castigos moderados" em suas práticas escolares.

Assim, é bom frisar que, a partir da segunda metade do Oitocentos, inúmeras ações foram deflagradas com o intuito de coibir os castigos corporais, as palmatórias e outros meios de punição nas escolas ${ }^{6}$. Um dos defensores de sua proibição foi o Abílio Cesar Borges (Barão de Macaúbas), médico e fundador do Colégio Abílio na Corte. Mesmo notabilizando-se por sua peregrinação contra os castigos, o Barão também sucumbiu em denúncias conforme processo encontrado no Arquivo Geral da Cidade do Rio de Janeiro (CASTIGOS CORPORAIS, 1886, fl. 56-68), de fechamento do seu colégio por três meses no ano de 1886 (CASTIGOS CORPORAIS, 1886, fl. 56-68).

Enquanto isso, conflitos existentes entre as intenções das reformas educativas e as experiências dos sujeitos escolares se manifestavam na escola e na rua. $\bigcirc$ professor público Antonio Estevão da Costa e Cunha ${ }^{7}$ se insurgiu contra o tempo escolar prescrito nas normas da instrução pública em reação às "tropelias de meninos na rua", que entravam em conflito com alunos de outros colégios, além de se unirem a "garotos e capoeiras para fazerem assuada na porta dos vizinhos e até na própria escola". A volta para a escola, na parte da tarde, criava a oportunidade para que escolares, garotos e capoeiras que perambulavam pelas ruas se dedicassem a todo tipo de desordens, fato intolerável para uma instituição consagrada à instrução e educação da mocidade. 
Além do mais, o horário escolar dava ensejo ao encontro indesejável de alunos com outras categorias de sujeitos que escapavam das ações educacionais promovidas por diferentes formas escolares distribuídas pela cidade: escolas, colégios, asilos e internatos para a educação de crianças e jovens ${ }^{8}$. As algazarras, arruaças e astúcias dos meninos induziram o professor a uma aplicação não usual do regulamento da instrução pública, determinado a dar as seis horas regulamentares de aula em apenas um turno, decisão comunicada ao poder público por meio de ofício encaminhado ao delegado do distrito literário onde se encontrava instalada a escola.

Participo a V. Ea . que desta data em diante não dou mais aula à tarde, responsabilizando-me por todas as consequências deste meu ato. Alguns dias de experiência foram bastantes para se reconhecer toda a inconveniência, sem razão e imoralidade até, que resultam de uma tal medida; fatos nunca reproduzidos nestas escolas e suas imediações, tropelias de meninos na rua, conflitos com alunos de outras escolas e colégios, reuniões com garotos e capoeiras para fazerem assuada na porta dos vizinhos e até na própria escola [...] (INSTRUÇÃO PÚBLICA, 1878, fl. 50-52).

De acordo com Costa e Cunha (2007), o prof. Estevão obteve autorização do Ministério do Império para dar aula em um só período, apresentando ao Conselho Diretor da Instrução Pública o ofício em que a Regente Princesa Isabel atende às suas solicitações. Não é possível compreender o ocorrido, apenas, como a obtenção de uma "graça" da autoridade imperial, sem considerar a reivindicação de um professor público e as resistências dos alunos à disciplina escolar.

A descrição dessas ocorrências aponta para uma direção importante que será desenvolvida ao longo deste texto: fisgar como algumas crianças elaboraram, formularam, e constituíram as suas ações sociais e, ao mesmo tempo, entender as suas formas de agir no cotidiano da cidade a par da atuação do poder público?. São crianças que zanzam e se envolvem em lutas corporais, pelas ruas; vão às escolas, provocam e são provocadas pelos professores; algumas são premiadas e punidas; outras exercem um ofício e são exploradas no trabalho doméstico e nas fábricas; esse é o alvo.

Como o leitor já teve a oportunidade de conferir, este trabalho recorre a um corpus documental variado, constituído por ofícios, leis e obras de alguns dos reformadores que se dedicaram a analisar, propor e implementar ações 
As tropelias e assuadas de escolares e garotos na cidade do Rio de Janeiro entre os séculos XIX e XX

de intervenção sobre as infâncias da cidade. Diante do volume de fontes, optou-se por trabalhar somente com um periódico, a Gazeta de Notícias que se mostrou particularmente sensível aos temas da educação e da proteção à infância, não obstante ocupassem as páginas de outros jornais que circulavam pela cidade ${ }^{10}$.

Assim, este artigo está dividido em três partes. Na primeira, optou-se por apontar as contradições entre as experiências dos sujeitos no processo de escolarização. Destaque a ser dado aos castigos corporais empregados - de forma frequente pelos professores nas escolas -, e denunciados na imprensa carioca como medida educativa que deveria ser abolida. Na segunda, são visadas as reformas que buscaram coibir essas práticas, em paralelo com a proliferação de um aparato assistencial (público e privado) constituído de forma desarticulada e fragmentada, no final do Oitocentos e início do Novecentos, destinado à educação moral da infância. Por último, são empregadas as reflexões do desembargador Ataulpho de Paiva que destaca a articulação da ação do poder público com a iniciativa privada tendo como substrato importante das ações assistenciais a solidariedade humana no combate à pobreza.

\section{Conflitos entre as experiências dos sujeitos escolares: os castigos corporais}

O uso dos castigos corporais pelos professores, aplicados como medida educativa encontrava amparo legal no Código Criminal de 1830. Considerado como crime justificável, o "castigo moderado" aplicava-se quando o mal consistia nas seguintes situações: "[...] os pais derem a seus filhos, os senhores a seus escravos, e os mestres a seus discípulos desde que não contrória à lei em vigor" (CÓDIGO CRIMINAL, 1830, Art. 14, § 6\%). No entanto, a legislação específica da instrução pública, como o Regulamento de 1854, não confirmou a sua determinação, embora não os tenha proibido explicitamente. As prescrições e os "esquecimentos", inscritos na Reforma Couto Ferraz, dialogavam com as práticas pedagógicas amparadas pela cultura escolar ${ }^{11}$, cujos agentes resistiam a abandonar antigos costumes que permeavam as relações entre professores e alunos.

"Ler a escola lendo a cidade" (NUNES, 1996, p. 155) nos remete à ideia de compreender a cultura engendrada na escola por seus sujeitos (e 
não somente pelas imposições das reformas educativas) na relação com a(s) cultura(s) constituídas(s) nos diversos espaços sociais onde circulam: na família, na fábrica, na oficina, nas ruas, nos locais de lazer e de realização dos rituais religiosos, enfim, nos meios heterogêneos de aprendizado e socialização dos indivíduos, desde a mais tenra idade. $\bigcirc$ castigo como prática social fazia parte da vida das crianças e dos jovens, presente nos vários espaços onde circulava. Amparado na concepção de dispositivo disciplinar, o castigo físico adentrou a escola republicana, conforme levantamento realizado por Arthur Ramos na década de 1930 (NUNES, 1996). Não trabalhamos com a hipótese da cultura escolar como um instrumento de resistência às mudanças, mas considerando as tensões entre a persistência das práticas costumeiras e a invenção, como também a "invenção de tradições". Assim, não basta apontar que determinados costumes, de professores e alunos, resistiam à mudança, mas buscar entender os seus sentidos, o porquê de sua persistência no tempo e no espaço e de que modo se tornam focos de lutas, polêmicas e disputas.

Vale apresentar que, embora os modelos de civilização e modernidade se orientassem pelos das cidades europeias, o uso do castigo escolar, tema polêmico nas últimas décadas do Império e no início do regime republicano, era permitido em vários países considerados cultos e civilizados. A Gazeta de Notícias, em princípios do século XX, empreendeu uma campanha centrada em denúncias contra castigos abusivos praticados por instituições oficiais do Distrito Federal, como a Escola Quinze de Novembro, a Companhia de Aprendizes Marinheiros e a Casa de Detenção, e por colégios e asilos particulares. Tais práticas, identificadas com o passado escravista, não condiziam com a imagem que o país construía para si. Em tom mais moderado, porém, com certa dose de crítica, o jornal relata que "Na Allemanha e na Inglaterra os castigos corporaes nos collegios são ainda hoje muito usados. Na Inglaterra, sobretudo, o uso da vara é frequente mesmo nos collegios femininos" (EXTERIOR, 1903, p. 1).

Tal questão propicia perceber que, mesmo havendo a circulação de intelectuais entre Brasil, países da Europa e Estados Unidos, as medidas aqui implantadas eram adaptadas e tinham seus interesses e seus distintos referenciais ampliados e mesclados. Entre os intelectuais brasileiros que atuavam sobre as questões educacionais e que se posicionavam contrariamente ao uso dos castigos corporais nas escolas destaca-se Manoel Francisco Correia. $\bigcirc$ intelectual, senador do Império, e Ministro de Estado dos Negócios 
As tropelias e assuadas de escolares e garotos na cidade do Rio de Janeiro entre os séculos XIX e XX

Estrangeiros a partir de 1877, também é apontado como o responsável pela organização das "Conferências Populares" (1 873-1 890), encontros marcados por fecunda discussão acerca das ideias científicas e pedagógicas no Rio de Janeiro (BASTOS, 2002) $)^{12}$. Segundo Manoel Francisco Correia,

Para corrigir meninos nada há mais improprio que pancadas, castigos que inspira-thes natural aversão a cousas que aliás o professor deve esforçar-se por fazer amar. Nada mais comezinho do que ver os meninos odiarem logo certas cousas desde que a ellas são constrangidos por meio de pancadas (CORREIA, 1876, p. 13).

Dentre toda a discussão, nota-se que o reconhecimento e as ações diferenciadas para os "piores" e "melhores" alunos estiveram presentes no processo de modernização das práticas escolares no Brasil entre o século XIX e XX. O movimento escolar de "punir" e/ou "premiar" adquiriu fórum privilegiado de discussão ${ }^{13}$. A sua repercussão estava presente nos periódicos. Assim, em 16 de fevereiro de 1890, foi publicado na Gazeta de Notícias artigo que apresentou considerações sobre "A disciplina e a educação moral" no ensino secundário. Entre os conselhos pedagógicos informados aos leitores, o autor

168 propõe que haja reunião periódica entre os professores e direção escolar para apresentar os "juízos e suas impressões sobre os alunos" e "a aplicação de notas justas, bem fundamentadas, que são verdadeiras sanções, e tanto mais eficazes, quanto o aluno não tem a epiderme embotada pela repreensão de cada dia ou pelos castigos dados a torto e a direito." A respeito dos castigos aplicados quando houver infração, recomenda que a correção não fosse pautada em "[...] velhas penalidades físicas, o seqüestro, a privação do movimento e de recreios" (ENSINO SECUNDÁRIO, 1890, p. 1).

Ainda destaca que a prática da premiação "também contribui para animar os bons trabalhadores." O elogio do mestre, a aprovação, o reconhecimento dos "esforços meritórios" nortearia a prática pedagógica. A premiação seria destinada a todos os alunos que "[...] com o ótimo trabalho conseguiram uma determinada média de notas [...]", privilegiando-se dois tipos: "[...] o de excelência, destinado ao aluno mais distinto pelo procedimento, pelo trabalho e pelas provas, e o de honra ao que pelo caráter, pelo procedimento, pelo esforço próprio, houver merecido no mais alto ponto a estima de seus mestres" $^{\prime 14}$ (ENSINO SECUNDÁRIO, 1890, p. 1). 
No mesmo tom, o autor do artigo recomenda a adoção de um sistema de premiação pautado no trabalho exercido por cada aluno no decorrer do ano letivo, para alcançar a excelência escolar, com base na máxima de que "[...] quem mais merece não é o talento, é o trabalho." $\bigcirc$ desenvolvimento do hábito do trabalho como meio para a superação do estado natural, responsável pelos desvios sociais, e caminho para livrar a sociedade dos vícios, compunha o vocabulário escolar e estava atrelado e respaldado pelas noções de modernidade, ordem e progresso. A presença de métodos pedagógicos pautados na noção de trabalho pode ser compreendida também como legitimação do projeto de transição do trabalho escravo para o trabalho livre no transcorrer do século XIX.

Portanto, as campanhas abraçadas em torno do fim dos castigos corporais tinham, na escolarização das crianças e dos meninos, a sua preocupação. A escola e os novos métodos de ensino deveriam reservar um lugar privilegiado ao trabalho, associado à formação moral da infância. Estes representavam os sentidos da modernidade educacional em meio à expansão do assalariamento da mão de obra no Oitocentos.

\section{Reformas da instrução, desordens na assistência e a educação da infância}

Num período marcado por profundas transformações (sociais, econômicas, políticas e culturais), alguns reformadores, na cidade do Rio de Janeiro, da Belle Époque, destinaram à educação da infância desvalida e "moralmente abandonada" - considerada como "perigosa" e daninha à ordem social -, uma atenção especial.

termo reforma educativa, como vem sendo apreendido pelo campo da história da educação, apresenta-se com múltiplos sentidos, envolvendo diferentes nexos que se articulam: a extensão do governo sobre a população por meio da regulamentação da instrução pública (GONDRA, TAVARES, 2004); as intervenções do poder público sobre as instituições educacionais por meios legais (PAULILO, 200 1, 2010); as ações, negociações e subversões dos sujeitos, a despeito da força da lei. Neste sentido, a reforma situa-se nos campos jurídico e educativo, constituindo-se enquanto prática social marcada por disputas e lutas sociais e políticas (GVIRTZ; VIDAL; BICCAS, 2009). Nesta 
perspectiva, a instituição educacional emerge como "[...] lugar de conflito e consenso, produzidos social e historicamente [...]" e a reforma resulta da "[...] ação de múltiplos sujeitos sociais [...]": "[...] acadêmicos, políticos, professores, administradores, jornalistas, opinião pública e alunos" IGVIRTZ; VIDAL; BICCAS, 2009, p. 16-17). Dispondo de um repertório diversificado de representações sobre o papel das instituições educacionais e do papel do Estado, sob determinadas condições históricas, grupos se aliam no combate a costumes arraigados da cultura escolar, como o emprego de castigos corporais, e na defesa da extensão do poder do Estado sobre o setor privado dedicado à assistência e à educação de crianças. Nos debruçaremos sobre estas questões, partindo da hipótese de que a intenção de reformar dirigia-se a diferentes sujeitos e instituições no período inicial da República.

Assim, o jornal Gazeta de Notícias, em sua edição de 14 de fevereiro de 1890, publicou o Código de Posturas aprovado pelo Conselho da Intendência Municipal da capital federal. Duas seções do Código chamam a atenção, por intervir na criação e nas práticas pedagógicas das instituições assistenciais e educacionais. Na primeira, em seu título 1, Higiene e saúde pública, seção 4, Internatos, colégios, ginásios e outros estabelecimentos para 170 criação, educação e instrução de crianças; hospitais, enfermarias, casas de saúde e maternidades, loucos em casas particulares, determina-se que:

Nenhum internato, colégio, ginásio ou outro estabelecimento de associações ou de particulares, destinados à criação ou à educação e instrução de crianças, se poderá fundar, nem os já fundados poderão mudar de uma localidade para a outra sem licença da municipalidade. $\bigcirc$ infrator incorrerá na multa de $30 \$$ e na desobediência será fechado o estabelecimento (CÓDIGO DE POSTURAS, 1890, p. 3).

Na segunda, no artigo 46, os castigos corporais são expressamente proibidos nestes estabelecimentos:

Nos estabelecimentos de que trata esta postura, e, em geral, em todas as escolas públicas e particulares deste município, é proibido aplicar as crianças castigos físicos. Penas: multa de $20 \$$ e o dobro e oito dias de prisão em caso de reincidência (CÓDIGO DE POSTURAS, 1890, p. 31. 
O Código, destinado a regular as ações da população e das instituições na relação com a cidade, reafirma as tentativas do poder público de intervir e orientar no cuidado à infância, exigindo ainda o exame da localidade e do edifício pela Inspetoria Geral de Higiene para a concessão da licença ao impetrante (CÓDIGO DE POSTURAS, 1890).

O Governo Provisório, antecipando os debates em torno do formato político institucional de organização do Distrito Federal (1 892), buscava estabelecer as normas de convivência na cidade, incluindo os meios e modos de criar, instruir e educar crianças. Assim colocado, o consenso parecia imperar nos meios assistenciais e educacionais a serem regidos, num breve lapso de tempo, pela municipalidade. Conquanto as burlas às normas suscitassem denúncias junto aos jornais e à Diretoria de Instrução Pública e, provavelmente, à Diretoria de Higiene Pública, pois tais estabelecimentos podiam estar vinculados às duas instâncias de gestão e inspeção, fato é que as representações sobre a educação e a assistência à infância divergiam e geravam tensões entre representantes do poder público. Os conflitos chegavam ao público com as matérias publicadas nos jornais, que, por sua vez, forçavam os órgãos competentes a tomarem atitudes que podiam envolver diversas instâncias oficiais, como diretorias, escolas e delegacias de polícia, conforme o caso relatado no início deste artigo.

As denúncias contra professores que insistiam em castigar seus alunos e alunas continuam a aparecer, de forma esparsa e breve, no levantamento feito junto ao jornal Gazeta de Notícias, no período de 1890 e 1903. Contudo, o periódico centra sua artilharia em outras instituições que também atendiam a meninos, denominados nos artigos como "menores": a Escola Quinze de Novembro, a Companhia de Aprendizes Marinheiros, a Colônia Correcional de Dois Rios e a Casa de Detenção. Todas recebiam "menores", de acordo com as classificações estipuladas: menores abandonados e menores delinquentes, sendo que a Colônia Correcional estava localizada em área distante da cidade, na llha Grande. As três últimas não respondiam à municipalidade por estarem vinculadas a ministérios do Governo Federal, sugerindo o estabelecimento de uma hierarquização das tarefas e uma distribuição das infâncias entre as esferas de poder. Entre 1902 e 1903, estabelecimentos que internavam meninos recolhidos/apreendidos na cidade do Rio de Janeiro estiveram envolvidos em denúncias de castigos contra os internos veiculadas pela imprensa, sugerindo a existência de representações conflitantes quanto 
aos modos de educar e reformar uma parcela da população percebida como incompatível frente às reformas pretendidas para a capital da República ${ }^{15}$.

Um bom exemplo são os estabelecimentos criados pela iniciativa particular do ex-praça do corpo militar de polícia da Corte, dito "pseudoprofessor", Domingos de Oliveira Menna Barreto, fundador de escolas e asilos para "crianças pobres, a maior parte sem pais", quando, em 1888, obteve da Inspetoria Geral de Instrução o diploma que o habilitava a ensinar matérias da instrução primária. Na edição do dia 17 de junho de 1890, intitulada, História de um professor, o jornalista da Gazeta de Notícias cita apontamentos do relatório do Dr. Thomaz Delfino, $2^{\circ}$ delegado de polícia, remetido no dia anterior ao Dr. Juiz do $9^{\circ}$ distrito criminal. A matéria, minuciosa, em tom indignado, reproduz uma série de denúncias contra Domingos, centradas nas fraudes quanto à criação das instituições e no tratamento dado aos alunos e alunas: andavam maltrapilhos, esfomeados, levavam bordoadas, além da desonra de uma jovem de 14 anos.

O Sr. Dr. $2^{\circ}$ delegado em uma visita que fez a escola da rua do Aqueduto n. 78, encontrou-a na maior miséria, imundice e anarquia; uma criança de 13 anos, que mal sabia ler, tinha a responsabilidade de outras onze, meninos e meninas naquele lugar afastado e mal habitado.

Diversas testemunhas juraram que Menna Barreto trazia crianças desta escola maltrapilhas, sujas e esfomeadas, e o que mais é, que as esbordoava.

Deu origem ao inquérito o fato da queixa por Gertrudes Brígida Teixeira ao Dr. Thomaz Delfino, sobre o desaparecimento de sua filha Leonor, de 14 anos de idade, que havia entregue na escola Princesa Isabel, a Menna Barreto, e que, depois de grande peregrinação e trabalho, foi Gertrudes encontrar sua filha, suja, com contusões e queimaduras, queixando-se de sofrer fome e castigos corporais e de que o diretor Menna Barreto tentara seduzi-la (HISTÓRIA DE UM PROFESSOR, 1890, p. 1).

Uma "criança de treze anos", despreparada para a tarefa, era responsável por outras, o que resultou na indignação do jornalista responsável pela extensa matéria publicada no jornal. Pela cidade, sabe-se que instituições públicas nem sempre ofereciam o tratamento propugnado nos regulamentos, tornando-se, eventualmente, alvos de denúncias na imprensa, mas nem sempre de uma forma tão minuciosa e documentada como o arrazoado contra Menna 
Barreto. $\bigcirc$ que estava em jogo não eram somente as representações acerca dos melhores meios de corrigir a criança dita "incorrigível", mas visões divergentes sobre o controle do Estado sobre as iniciativas e instituições privadas de educação e assistência à infância. A história de um professor, narrada no jornal, enfatiza suas oportunidades de criação:

Não obstante the dar o diploma e o direito de abrir colégios, contudo, abriu-os ou melhor, simulou abri-los e pôs em prática o programa da Propagadora da Instrução Popular.

Sempre que, desde 1888, a popularidade apanha um nome e o destaca, acude Menna Barreto com uma escola.

Assim é que criou a Escola Rodrigo Silva, a travessa do Desterro, a Escola Visconde de Figueiredo, a rua do Resende, n.43, a Escola Princesa Isabel, a rua Pereira da Silva, a Escola Paula Mayrink, a rua do Riachuelo n. 153, a Escola Mello Barreto e finalmente a Escola Marechal Deodoro.

Igualmente criou o Apostolado da Infância Popular, o Orfelinato do Exército e da Armada e o Núcleo Agrícola e Industrial do Brasil, cuja seção orfanológica ficava estabelecida na rua do Aqueduto, n.78.

No seu interrogatório afirmou Menna Barreto que existia na mesma rua uma outra escola sob a denominação de Imaculada Conceição.

No meio de tanta criação, ainda publicou um jornal $\bigcirc$ Baluarte, que teve dois números; negociava plantas medicinais e tinha a sua agência de charutaria da rua da Misericórida n. 33.

Para explorar o próximo fazia acreditar, começando naturalmente pelas pessoas cujos nomes aproveitava para pretexto e anúncio, na realidade de empresas destinadas a instruir e fazer caridade as crianças (HISTÓRIA DE UM PROFESSOR, 1890, p. 1, grifo nosso).

A facilidade para abrir estabelecimentos de caridade, a falta de fiscalização por parte do poder público e a exploração da boa fé dos doadores são temas abordados no jornal. Dois anos depois, o mesmo periódico, ao veicular uma denúncia contra a Escola Quinze de Novembro, fundada em 1899 pela iniciativa de João Brasil Silvado (chefe de polícia) ${ }^{16}$, aproveitou o ensejo para mobilizar a opinião pública em favor da proposta do juiz Ataulpho de Paiva para a fundação de uma Repartição Central de Assistência para fiscalizar os asilos. 
Nós estamos em uma terra em que qualquer sujeito, vindo de qualquer parte, pode fundar um asilo. Funda-o, e começa a arrebanhar crianças. Afluem os donativos, a imprensa põe nas nuvens a alma caridosa que assim se preocupa com a sorte da infância desvalida, todos os tambores da reclame rufam freneticamente em torno dessa obra meritória, - e ninguém pensa em ir verificar nesses asilos, nessas casas de caridade, que espécie de caridade é a que nelas se pratica. Há autoridades que têm o dever de fazê-lo: mas o tempo é tão curto, e o trabalho tão pesado!... e, um belo dia, graças ao acaso ou a providência de uma denúncia anônima, chega a gente ao conhecimento de que a caridade dessas boas almas protetoras da infância é como a caridade do Diabo, que, as vezes, para com mais comodidade chegar aos seus fins, dá para fingir de S. Francisco de Assis... Já houve por ai cinco ou seis asilos de caridade que eram casas de tortura e de depravação. Em um deles, verificou-se mesmo, há uns seis ou sete anos, que as crianças passavam fome e sede, e sofriam castigos corporais hediondos, enquanto dois apaniguados do diretor tocavam tambor e trombeta para abafar o gemido das vitimas.

Pois bem. Há poucos meses, um juiz, o Dr. Ataulpho de Paiva, num artigo publicado no Jornal do Commercio, lembrava a necessidade da fundação de uma Repartição Central de Assistência, especialmente incumbida de fiscalizar os asilos. A troça nacional tomou conta do assunto, e matou a tentativa a frenhadas de ridículo! (CHRONICA, 1902, p. 1).

jornalista ironiza a oposição recebida pela campanha de Ataulpho de Paiva, trazendo indícios das disputas e dos interesses envolvidos na criação desses estabelecimentos. E mostra-se pessimista quanto ao empenho dos órgãos públicos em investigar o "escândalo", deixando-o cair no "esquecimento".

Depois do escândalo é que vêm as queixas, as polêmicas, os relatórios, as primeiras providências espalhafatosas... e o esquecimento. Querem apostar? Daqui um mês, sem que se chegue a saber com segurança o que houve e o que há na Escola Quinze de Novembro, está tudo na pasmaceira, e não se trate mais disso (CHRONICA, 1902, p. 1).

Em torno dessa "pasmaceira" se mobilizou o então juiz Ataulpho Nápoles de Paiva. Em 1903, reuniria em livro um conjunto de artigos publicados na imprensa, onde denunciaria os problemas da assistência oficial nesse 
período. Para Ataulpho de Paiva, a "caridade oficial" apresentava-se como: "irrefletida", "de duração efêmera e de efeitos inteiramente nulos", "desorganizada", dispersa e sem um "rígido controle" (PAIVA, 1903, p. 89).

A "caridade oficial" mal praticada mobilizaria alguns intelectuais de proa em torno da construção de uma "verdadeira beneficência" (PAIVA, 1903, p. 16). A sua campanha em torno da criação da Repartição Central de Assistência tinha como objetivo a organização da assistência pública em outros moldes. Da antiga "caridade oficial" deveria herdar apenas a "solidariedade humana" e o "sentimento humanitário". A partir desses princípios, a campanha estava centrada na "[...] aliança entre a assistência pública e assistência privada" (PAIVA, 1903, p. 91). Essa demarcaria uma nova concepção de assistência, pautada por uma nova beneficência: a filantropia jurídica, de caráter científico e com rígido controle por parte dos órgãos públicos.

\section{Assistência pública e privada: alinhavos e costuras}

Como visto anteriormente, a disseminação, a desorganização e a fragmentação da "caridade oficial" tiveram como diapasão, no período republicano, a garantia da livre iniciativa na constituição de associações de caráter civil, fossem elas mutualistas, filantrópicas, sindicais, artísticas, recreativas, profissionais etc ${ }^{17}$. Com exceção das sociedades de resistência, tais como os sindicatos que precisavam do registro no cartório, além do envio de uma cópia de seus Estatutos à Junta Comercial de cada estado, as exigências para a criação de associações eram relativamente fáceis de cumprir ${ }^{18}$.

É nesse rescaldo de cultura política que a trajetória profissional de Ataulpho Napoles de Paiva (1865-1955), iniciada ainda ao final do XIX, paulatinamente teve na discussão e na ação sobre a assistência uma de suas preocupações. Em 1900, como sócio-fundador da Liga Brasileira Contra a Tuberculose - atualmente Fundação Ataulpho de Paiva (FAP) ${ }^{19}$ - , estava imerso e era um observador atento em relação à profusão de estabelecimentos privados e dispersos em suas finalidades.

Por outro lado, já demarcando um território intelectual que iria ocupar de maneira vertiginosa, em 1903 toma parte dos trabalhos do Congresso Internacional de Assistência Pública e Privada em Paris. Desde então, assume de forma cada vez mais intensa, na imprensa e na publicação de livros, as suas 
As tropelias e assuadas de escolares e garotos na cidade do Rio de Janeiro entre os séculos XIX e XX

ideias em organizar e sistematizar o que denominaria de assistência metódica: ao mesmo tempo científica e estabelecendo uma aliança entre a assistência pública e privada. Para tal, defende a criação do Ofício Geral de Assistência, órgão encarregado de organizar, controlar e fiscalizar as ações das associações da sociedade civil, na capital federal ${ }^{20}$. Aliás, trata-se de um modelo inspirado na experiência francesa (RIZZINI, 1993, p. 91).

Como delegado do Brasil, junto com Nina Rodrigues, em 1906, participa do Congresso Internacional de Milão. Publica no ano seguinte, Assistência Pública - o Brasil no Congresso de Milão (1906) entrevista realizada ao redator do jornal Notícia em que relata os pontos principais em torno da assistência, discutidos em Milão. Nesse momento, mais uma vez reforça e apresenta suas ideias sobre a questão (PAIVA, 1907).

Cada vez mais envolvido com a assistência, em 1908, é a vez de organizar, junto a Olavo Bilac, o Congresso Nacional de Assistência Pública e Privada com o mesmo prazo de duração da Exposição Naciona|${ }^{21}$, na cidade do Rio de Janeiro. Fazem parte desse Congresso nomes importantes ligados à assistência, médicos, juristas, literatos, jornalistas e higienistas, tais como: Moncorvo Filho, Franco Vaz, Afrânio Peixoto, Medeiros e Albuquerque,

176 Juliano Moreira, Paulo Barreto (João do Rio), Amaro Cavalcanti, Olavo Bilac etc. (DISTRITO FEDERAL, 1908). Dentre as teses apresentadas, destaca-se a de Ataulpho de Paiva versando sobre a "Assistência metódica - meios práticos para obter uma aliança permanente entre a assistência pública e a privada", tendo sido reproduzida integralmente no livro "Justiça e Assistência - os novos horizontes", de 1916.

Em 1922, ano da comemoração do centenário da independência do Brasil, a prefeitura do Distrito Federal fez publicar o livro, "Assistência Pública e Privada", sob a coordenação de Ataulpho de Paiva. Ao longo dos últimos anos, fora incumbido pelo então prefeito general Bento Ribeiro, em abril de 1913, de realizar um levantamento de todos os estabelecimentos de assistência no município. Trabalho de fôlego realizado com determinação e desprendimento, o qual grifou definitivamente o nome de Ataulpho de Paiva como grande fomentador da vinculação entre a assistência pública e a privada no Brasil 22 .

Nesse trabalho, fica evidente a importância das formas associativas $^{23}$ sejam elas as de auxílio mútuo ou as de beneficência. Para se ter uma 
ideia, o arrolamento de 1912 reúne um total de 438 associações localizadas no município do Rio de Janeiro, que filiaram 282.937 associados. Nesse ano, foram beneficiadas 834.624 pessoas com auxílios: funerários (7.983), pecuniários (23.714), médicos (762.538), de outra natureza (34.384) e não especificado (6.006) (PAIVA, 1922, p. 748). Percebe-se, nitidamente, o teor das preocupações de Ataulpho de Paiva ao defender um novo molde de assistência. $\bigcirc$ vigor dessas formas de associações permeava a vida de homens, mulheres e crianças fossem eles brasileiros ou estrangeiros. Destarte, se fazia necessário organizá-la.

Em defesa de uma assistência metódica, afirmava que "[...] chegamos ao extremo de apelar para a ação policial todas as vezes que entra em crise a função tutelar de nosso rudimentar aparelho de caridade e beneficência" (PAIVA, 1922, p. 2). Como reformador e compromissado com a "verdadeira" assistência, buscava identificar aqueles realmente necessitados com o intuito de distinguir os "verdadeiros mendigos" dos "profissionais". A filantropia jurídica parte de um ideal de "[...] justiça defensiva, preventiva e reparativa [...]" visando a "higiene social" por meio da educação e instrução. Para tal, é de suma importância a intervenção estatal, por meio do Ofício Geral de Assistência na fiscalização dos estabelecimentos de assistência pública e privada (PAIVA, 1922, p. 16-17). Além das doações realizadas pelo poder público, sem nenhum tipo de controle, era imprescindível evitar o desperdício. Ao menos dispor de recursos para os atos "nobres" da beneficência privada ${ }^{24}$.

\section{Considerações finais}

Ao longo do texto, buscou-se identificar as ações, as tropelias e as assuadas dos meninos que zanzavam pelas ruas da cidade. Em sua escolarização, os procedimentos de disciplinamento oscilavam entre as "premiações" e os "castigos". Os atos obscenos e as lutas corporais eram imediatamente repreendidos pelos professores, de vez em quando sendo "empurrados", outras vezes levavam "puxões de orelhas" e se "contundiam"; enfim, um repertório inesgotável de comedimentos. Ações e reações de alunos e professores geravam procedimentos administrativos, dos quais alguns registros foram preservados nos arquivos públicos. Indaga-se até que ponto condutas e atitudes vividas no cotidiano escolar interferiram nas reformas empreendidas pelo poder 
As tropelias e assuadas de escolares e garotos na cidade do Rio de Janeiro entre os séculos XIX e XX

público na instrução, movimento que dialogava com as redes constituídas pelos sujeitos escolares e representantes de instâncias diferentes da administração municipal ${ }^{25}$.

Por outro lado, pontuaram-se as formas associativas empreendidas pela sociedade civil de fisgar e apetecer esses meninos. De forma desorganizada e dispersa, indivíduos e grupos teriam promovido o conluio. Melhor dizendo, entra em cena Menna Barreto (o ex-praça) e responsável pela criação de instituições caritativas de assistência e instrução, além das denúncias de explorar os alunos e de tentar seduzir Leonor na escola Princesa Isabel. $\bigcirc$ caráter empreendedor do professor gerou revolta na imprensa, que, por sua vez, agregou vozes contra a o descontrole na criação de instituições assistenciais e educacionais.

Em meio a esse litígio, apresentou-se o reformador, o juiz, o escritor, o desembargador, o imortal ${ }^{26}$ e o Ministro do Supremo Tribunal Federal Ataulpho de Paiva. Em sua trova, um achado: a aliança entre a assistência pública e privada e a criação do Ofício Geral de Assistência. Em suma, deixa um legado insofismável: alinhavou e costurou relações entre o público e o privado e defendeu por meio da imprensa e dos impressos a assistência metódica, orientada

178 pelos princípios da higiene e pelos ditames da lei, a ser mantida sob o controle do Estado.

Ainda a reboque de suas afirmações, a iniciativa visava maior intervenção, por parte do Estado, sobre as ações das associações civis. A assistência metódica cumpria um papel singular no ordenamento das formas associativas existentes na então capital federal. Por meio da assistência privada, organização e recursos públicos, implicaria uma maneira de inibir e coibir as configurações organizativas das iniciativas populares, de trabalhadores, de professores, etc. Em última análise, dispunha-se a arrematar as tropelias e assuadas de escolares e garotos na cidade do Rio de Janeiro.

\section{Notas}

1 De acordo com o Decreto n. 1.331-A, de 17 de fevereiro de 1854, era uma das funções do Inspetor-Geral atuar nos casos de infrações disciplinares a que forem impostas as penas de admoestação, repreensão, ou multa (art. 2, $\S 11$ e art. 72). Além de inspecionar todas as escolas, colégios, casas de educação e estabelecimentos de instrução primária e secundária, públicos e particulares (art. $3^{\circ}, \S 1^{\circ}$. 
2 Consta em obra publicada em 1870 que o tradutor Charles Neucome Palmer era diretor do "American College S. Paul" (Collection of classical extracts approved by the Imperial Government... Rio de Janeiro: Typographia Franco-Americana, 1870).

3 Sobre a construção social do termo incorrigivel, ver o trabalho de Rizzini e Marques (2012).

4 Decorrido um pouco mais de um mês após o incidente com o professor, foi aprovado o Decreto n. 5.391, de 10 de setembro 1873, que estendeu aos estabelecimentos particulares de instrução da Corte as disposições do art. 72 (expulsão dos "incorrigíveis") e do art. 115 ("faltas" dos professores, como "exercer a disciplina sem critério") do Regulamento do ensino primário e secundário do Município da Corte, 1854.

5 Segundo o Jornal do Comércio, o fato ocorreu na Rua do Aqueduto, 23, situada em Santa Teresa. Na versão apurada pelo Inspetor junto ao aluno, segue a Rua S. Thereza, 23. Essas informações foram pinçadas do AGCRJ, códice 11.1.25, fls. 15 e 16, 1873.

6 A este respeito, ver Gondra e Sampaio (2010).

7 De acordo com Costa e Cunha (2007, p. 2), o prof. Estevão, formado em Farmácia (Ciências Naturais) pela Faculdade de Medicina do Rio de Janeiro, circulou por vários campos disciplinares e profissionais. Lecionou em diferentes instituições educacionais da cidade do Rio de Janeiro. Em 1878, atuava na terceira escola pública de meninos da Freguesia do Sacramento, área central da cidade.

8 A respeito da diversidade de formas escolares encontradas no Império, ver Gondra e Schueler (2008).

9 Ocorrências que continuaram a ser denunciadas nos jornais quando da mudança do regime político do país em 1889; contudo, optamos pela seleção dos casos apresentados em virtude da riqueza das descrições, envolvendo diferentes atores.

10 De acordo com Torres (2009, p. 139), a Gazeta de Notícias era um jornal de grande circulação na cidade. Fundada em 1875, inaugurou a forma de fazer jornais "baratos e populares", valendo-se das vendas avulsas feitas por pequenos jornaleiros. Nos anos de 1890, estima-se que o jornal atingia a marca de 35 mil exemplares diários.

11 A respeito das investigações sobre cultura escolar e de suas apropriações pela área da história da educação brasileira, ver a discussão realizada por Faria Filho, Gonçalves, Vidal e Paulilo (2004).

12 Sobre as "Conferências Populares da Glória" ver Bastos (2002), Fonseca (1 996), Carula (2007).

13 Castanha (2009) levanta a hipótese de que o recrudescimento nas práticas disciplinares estaria relacionado à popularização da escola na década de 1870 .

14 A Gazeta de Notícias publicava notas sobre os "prêmios escolares", nas quais eram destacados os alunos que se distinguiam dos demais, agraciados nas cerimônias públicas com troféus, livros e outros mimos, conforme se verifica nas edições dos dias 14/11/1901, 12/9/1903 e 17/9/1903.

15 Os artigos encontram-se na Gazeta de Notícias, nas seguintes datas: 20 de março de 1902; 10 de agosto de 1902; 10, 13 e 14 de março de 1903; 18 de outubro de 1903. 
16 Em 1903, a Escola Quinze de Novembro passou para as mãos do Estado, vinculada ao Ministério da Justiça e Negócios Interiores e regulamentada pelo decreto $n^{\circ} 4780$, de 2 de março de 1903. A respeito, ver estudo de Vianna (1999).

17 A Constituição de 1891, ao prever o direito de associação, definiu que caberia à polícia intervir apenas em caso de necessidade de manutenção da ordem pública (Art. 72).

18 De acordo com o Decreto n. 173, de 10 de setembro 1893, que regulava o art. 72, § 3, da Constituição de 1891, as associações que se fundarem para fins religiosos, morais, científicos, artísticos, políticos, ou de simples recreio, poderiam adquirir individualidade jurídica, inscrevendo o contrato social no registro civil da circunscrição onde estabelecerem a sua sede (art. $1 \%$. Ver Fonseca (2008).

19 Tornou-se seu presidente perpétuo, em 1937. Ver a este respeito, Fundação Ataulpho de Paiva (FAP). Disponível em: http://www.fundacaoataulphodepaiva.com.br/historia/. Acesso em: 16 jun. 2013.

20 O Decreto n. 441, de 26 de julho de 1903, cria no Distrito Federal o Ofício Geral de Assistência. Esse fato, como salienta Paiva (1922), contribuiu na elaboração da história e estatística de todos os estabelecimentos de caridade e assistência na cidade do Rio de Janeiro, anos mais tarde. Ao mesmo tempo, o decreto permaneceu letra morta. A este respeito ver Rizzini (1993, nota 23).

21 A Exposição Nacional de 1908 teve como objetivo as comemorações do centenário da abertura dos portos, no Rio de Janeiro, e ao mesmo tempo apresentar a reforma urbana da capital federal realizada no transcorrer da administração pelo engenheiro Francisco Pereira Passos (19031906). Sobre a exposição, ver Sily (2012).

22 Cabe mencionar que ao longo de sua trajetória profissional também foi Membro da Academia Brasileira de Letras (ocupando a cadeira 25), de 1916 a 1955, e seu presidente (1937). Além disso, Desembargador da Corte de Apelação do Distrito Federal (1905) e Ministro do Supremo Tribunal Federal (1934-1937).

23 Por associativismo temos "[...] um grupo formado por pessoas que se associam com base em um interesse comum e cuja participação não é obrigatória nem determinada por nascimento, e que existe independentemente do Estado" (FONSECA, 2008, p. 15).

24 Um exemplo de apoio aos atos "nobres" em prol da assistência privada é o Decreto n. 1.154, de 07/01/1904, pelo qual, o Presidente da República ficou autorizado a apoiar a instalação da sede do Instituto de Proteção e Assistência à Infância do Rio de Janeiro. Esta instituição foi inaugurada em 1901, por meio da iniciativa particular (Moncorvo Filho) com subvenção federal (RIZZINI, 1993, p. 180).

25 A respeito da participação de professores/as nas redes clientelares constituídas pelos intendentes, gerando tensões entre a prefeitura e o conselho municipal na gestão da instrução pública na cidade do Rio de Janeiro entre 1892 e 1902, ver Torres (2009).

26 Como membro da ABL, foi o terceiro a ocupar a cadeira de n. 25, de 1916 a 1955, sucedendo a Artur Orlando da Silva e precedido por José Lins do Rego. Ataulpho de Paiva na ABL. Disponível em: http://www.academia.org.br/abl/cgi/cgilua.exe/sys/start.htm? sid=255. Acesso em: 24 jun. 2013. 


\section{Referências}

BASTOS, Maria Helena Camara. Conferências Populares da Freguesia da Glória 11873 - 1890). In: CONGRESSO BRASILEIRO DE HISTÓRIA DA EDUCAÇ̃̃O, 2; 2002. Natal. Anais... Natal: Universidade Federal do Rio Grande do Norte, 2002. Disponível em: http://www.sbhe.org.br/novo/congressos/cbhe2/pdfs/Tema3/3104.pdf. Acesso em: 18 maio 2013.

BRASIL. Constituição da República Federativa do Brasil, de 24 de fevereiro de 1891. Disponível em: http://www.planalto.gov.br/ccivil_03/constituicao/constituicao91.htm. Acesso em: 4 ago. 2014.

Código Criminal do Brasil, Lei de 16 de dezembro de 1830. Disponível em: http://www. planalto.gov.br/ccivil_03/leis/lim/lim-16-12-1830.htm. Acesso em: 4 ago. 2014.

Decreto $\mathrm{n}^{\circ}$ 1.331, de 17 de fevereiro de 1854. Aprova $\circ$ Regulamento para a reforma do ensino primario e secundario do Municipio da Côrte. Disponível em: http:// www2.camara.leg.br/legin/fed/decret/1 824-1899/decreto-1331-a-17-fevereiro-1854590146-norma-pe.html. Acesso em: 4 ago. 2014.

Decreto ${ }^{\circ}$ 5.391, de 10 de setembro de 1873. Torna extensivas aos Estabelecimentos particulares de instrução primária e secundária do Municipio da Côrte as disposições dos arts. 72 e 115 do Regulamento de 17 de Fevereiro de 1854. Disponível em: http://legis. senado.leg.br/legislacao/ListaPublicacoes.action? id=8301 8\&tipoDocumento=DEC\&tipoTe xto=PUB Acesso em: 4 ago. 2014.

Decreto $\mathrm{n}^{\circ}$ 173, de 10 de setembro 1893. Regula a organização das associações que se fundarem para fins religiosos, morais, científicos, artísticos, políticos ou de simples recreio, nos termos do art. 72, § 30, da Constituição. Disponível em: http://legis.senado. leg.br/sicon/index.html\#/pesquisa/lista/documentos Acesso em: 4 ago. 2014.

Ministros: Ataulpho Nápoles de Paiva. Supremo Tribunal Federal. Disponível em: http://www.stf.jus.br/portal/ministro/verMinistro.asp?periodo=stf\&id=212. Acesso em: 16 jun. 2013.

CARULA, Karoline. As Conferências Populares da Glória e a difusão da ciência. Revista Almanack Braziliense, São Paulo, n. 6, p. 86-100, nov. 2007. 
As tropelias e assuadas de escolares e garotos na cidade do Rio de Janeiro entre os séculos XIX e XX

CASTANHA, André Paulo. A prática dos castigos e prêmios na escola primária do século XIX: do legal ao real. Revista Educere et Educare, Cascavel (Paraná), v. 4, n. 8, p. 245259, jul./dez. 2009.

CASTIGOS Corporais. Instrução pública. Rio de Janeiro, 1873. (Arquivo Geral da Cidade do Rio de Janeiro - AGCRJ. Códice 1 1. 1.251.

CASTIGOS Corporais. Instrução pública. Rio de Janeiro, 1886. (Arquivo Geral da Cidade do Rio de Janeiro - AGCRJ. Códice 1 1.1.251.

CÓDIGO de posturas. Gazeta de Notícias, Rio de Janeiro, n. 45, p. 3, 14 fev. 1890.

CORREIA, Manuel Francico. Educação na família e na escola. Conferências Populares, 1876, n. 6. Disponível em: http://memoria.bn.br/DOCREADER/DOCREADER. $\mathrm{ASPX}$ $\mathrm{BIB}=278556$. Acesso em: 5 maio 2013.

CUNHA, Beatriz da Costa e. "A arte é longa e a vida breve!": a trajetória de Antonio Estevam da Costa e Cunha, professor primário na Corte Imperial. In: ENCONTRO DE HISTÓRIA DA EDUCAÇÃO DO RIO DE JANEIRO, 1; 2007, Rio de Janeiro. Anais... Rio de Janeiro: Universidade Federal do Rio de Janeiro, 2007. 1 CD-ROM.

CHRONICA. Gazeta de Notícias, Rio de Janeiro, p. 1, 10 ago. 1902.

DISTRITO FEDERAL. Decreto $\mathbf{n}^{\circ} \mathbf{4 4 1}$, de 26 de julho de 1903. Cria no Distrito Federal o Ofício Geral de Assistência. In: PAIVA, Ataulpho de. Assistência pública e privada no Rio de Janeiro: história e estatística. Rio de Janeiro: Typografia do Annuario do Brasil, 1922.

Congresso Nacional de Assistência Pública e Privada. Capital Federal, Typographia do Instituto Profissional Masculino, 1908.

ENSINO SECUNDÁRIO. Gazeta de Notícias, Rio de Janeiro, p. 1, 16 fev. 1890.

EXTERIOR. Gazeta de Notícias, Rio de Janeiro, p. 1, 11 out. 1903.

FARIA FILHO, Luciano Mendes; GONÇALVES, Irlen Antônio; VIDAL, Diana Gonçalves; PAULLLO, André Luiz. A cultura escolar como categoria de análise e como campo de investigação na história da educação brasileira. Revista Educação e Pesquisa, São Paulo, v. 30, n. 1, p. 139-159, jan./abr. 2004.

FONSECA, Maria Rachel Fróes da. As "Conferências Populares da Glória": a divulgação do saber científico. Revista História, Ciência e Saúde Manguinhos, Rio de Janeiro, v. 2, n. 3, p. 135-166, nov./fev. 1996. 
FONSECA, Vitor Manoel Marques. No gozo dos direitos civis - associativismo no Rio de Janeiro, 1903-1916. Rio de Janeiro: Arquivo Nacional; Niterói: Muiraquitã, 2008.

GONDRA, José Gonçalves; SAMPAIO, Thiago. Ciência pela força? Dr. Abílio Cesar Borges e a propaganda contra o emprego da palmatória e outros meios aviltantes no ensino da mocidade (1856-1876). Acta Scientiarum Education, Maringá, v. 32, n. 1, p. 75-82, 2010.

GONDRA, José Gonçalves; SCHUELER, Alessandra. Educação, poder e sociedade no império brasileiro. São Paulo: Cortez, 2008.

GONDRA, José Gonçalves; TAVARES, Pedro Paulo Hausmann. A instrução reformada: ações de Couto Ferraz nas províncias do Espírito Santo, Rio de Janeiro e na Corte Imperial. In: CONGRESSO BRASILEIRO DE HISTÓRIA DA EDUCAÇÃO, 3; 2004. Anais... Curitiba: Pontifícia Universidade Católica do Paraná, 2004. Disponível em:http://www.sbhe.org. $\mathrm{br} /$ novo/congressos/cbhe3/Documentos/Individ/Eixo3/211.pdf. Acesso em: 10 maio 2013.

GVIRTZ, Silvina; VIDAL, Diana; BICCAS, Maurilane. As reformas educativas como objeto de pesquisa em História Comparada da Educação na Argentina e no Brasil. In: VIDAL, Diana; ASCOLANI, Adrián (Org.). Reformas educativas no Brasil e na Argentina: ensaios de história comparada da educação (1820-2000). São Paulo: Cortez, 2009.

HISTÓRIA de um professor. Gazeta de Notícias. Rio de Janeiro, p. 1, 17 jun. 1890.

INSTRUÇÃO pública. Oficio do prof. Antonio Estevão da Costa e Cunha ao Sr. Dr. Fernandes Peres Ferreira (Delegado deste distrito literário), em 17 de julho de 1878. Rio de Janeiro, 1878. (Arquivo Geral da Cidade do Rio de Janeiro - AGCRJ. Códice 1 1.4.30).

NUNES, Clarice. Cultura escolar, modernidade pedagógica e política educacional no espaço urbano carioca. In: HERSCHMANN, Micael; KROPF, Simone; NUNES, Clarice. Missionários do progresso: médicos, engenheiros e educadores no Rio de Janeiro (18701937). Rio de Janeiro: Diadorim, 1996. p. 155-224.

PALMER, Charles Neucome. Collection of classical extracts approved by the Imperial government... Rio de Janeiro: Typographia Franco Americana, 1870.

PAIVA, Ataulpho de. Assistência pública - sua função jurídica. Rio de Janeiro: Tipografia do Jornal do Commercio de Rodrigues \& C., 1903.

Assistência pública - o Brasil no Congresso de Milão (1906). Primeiras notícias. Rio de Janeiro: Imprensa Nacional, 1907. 
As tropelias e assuadas de escolares e garotos na cidade do Rio de Janeiro entre os séculos XIX e XX

Justiça e assistência - os novos horizontes. Rio de Janeiro. Tipografia do Jornal do Commercio, 1916.

Assistência pública e privada no Rio de Janeiro: história e estatística. Rio de Janeiro: Typografia do Annuario do Brasil, 1922.

PAULILO, André Luiz. Uma historiografia da modernidade educacional. Estudos Históricos, Rio de Janeiro, v. 23, n. 45, p. 27-49, jan./jun. de 2010.

Reforma educacional e sistema público de ensino no Distrito Federal na década de 1920 (tensões, cisuras e conflitos em torno da educação popular). 2001. Dissertação (Mestrado em Educação) - Programa de Pós-Graduação em Educação, Universidade de São Paulo, São Paulo, 2001.

RIO DE JANEIRO. Fundação Ataulpho de Paiva. Disponível em: http://www.fundacaoataulphodepaiva.com.br/historia/. Acesso em: 16 jun. 2013.

RIZZINI, Irma. Assistência à infância no Brasil: uma análise de sua construção. Rio de Janeiro: Editora Universitária Santa Úrsula, 1993.

RIZZINI, Irma; MARQUES, Jucinato de Sequeira. Os incorrigíveis da cidade: um estudo sobre a distribuição e circulação das infâncias na capital federal nas décadas de 1900 e 1910. In: LOPES, Sonia de Castro; CHAVES, Miriam Waidenfeld (Org.). A história da educação em debate: estudos comparados, profissão docente, infância: família e lgreja. Rio de Janeiro: MAUAD X/FAPERJ, 2012.

SILY, Paulo Rogério Marques. Casa de ciência, casa de educação: ações educativas do Museu Nacional (1818-1935). 2012. 399f. Tese (Doutorado em Educação) - Programa de Pós-Graduação em Educação, Universidade do Estado do Rio de Janeiro, Rio de Janeiro, 2012.

TORRES, Rosane dos Santos. Filhos da pátria, homens pelo progresso: ○ Conselho Municipal e a Instrução Pública na Capital Federal (1892-1902). 2009. 172f. Dissertação (Mestrado em História) - Programa de Pós-Graduação em História Social, Faculdade de Formação de Professores, Universidade do Estado do Rio de Janeiro, São Gonçalo, 2009.

VIANNA, Adriana de Resende Barreto. O mal que se adivinha: polícia e menoridade no Rio de Janeiro, 1910-1920. Rio de Janeiro: Arquivo Nacional, 1999. 
Profa. Dra. Irma Rizzini

Universidade Federal do Rio de Janeiro

Faculdade de Educação

Programa de Pós-Graduação em Educação

Grupo de Pesquisa Programa de Estudos e Documentação Educação e Sociedade | PROEDES | UFRJ

E-mail | irma.rizzini@gmail.com

Prof. Ms. Jucinato de Sequeira Marques Universidade Federal do Rio de Janeiro

Faculdade de Educação

Programa de Pós-Graduação em Educação

Grupo de Pesquisa Programa de Estudos e Documentação Educação e Sociedade | PROEDES| UFRJ

E-mail | jucinato@uol.com.br

Doutorando Vinicius de Moraes Monção Universidade Federal do Rio de Janeiro

Faculdade de Educação

Programa de Pós-Graduação em Educação

Grupo de Pesquisa Programa de Estudos e Documentação Educação e Sociedade |

PROEDES| UFRJ

Bolsista FAPERJ

E-mail | vinimoncao@gmail.com

Recebido 21 ago. 2014

Aceito 10 dez. 2014 